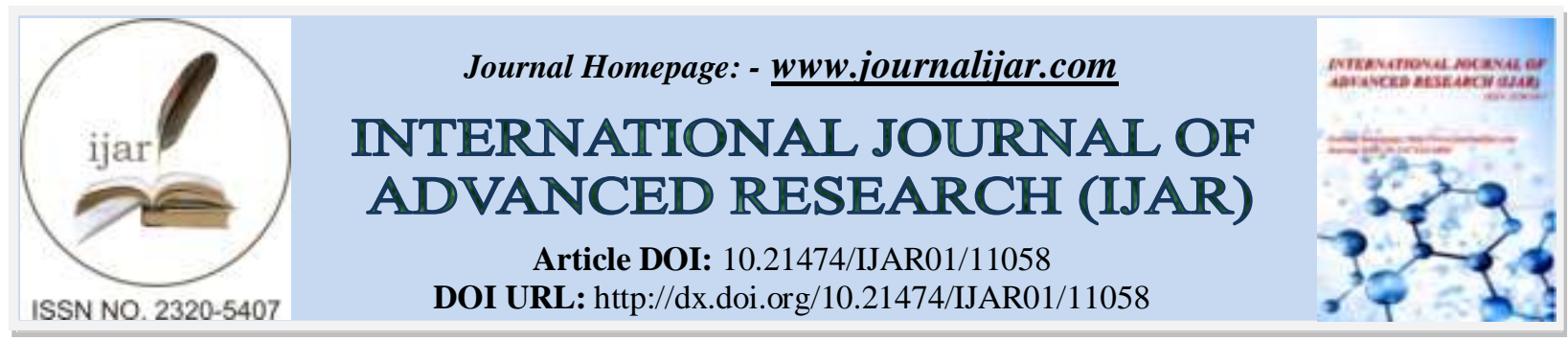

RESEARCH ARTICLE

\title{
THE RELATIONSHIP BETWEEN BODY MASS INDEX AND BLOOD PRESSURE OF ADULT AGE IN MUSSAYIB DISTRICT
}

\begin{tabular}{|c|c|}
\hline Manuscript Info & Abstract \\
\hline $\begin{array}{l}\text { Manuscript History } \\
\text { Received: } 25 \text { March } 2020 \\
\text { Final Accepted: } 30 \text { April } 2020 \\
\text { Published: May } 2020 \\
\text { Key words:- } \\
\text { Anabolic, Supplement, Gym, } \\
\text { Knowledge }\end{array}$ & $\begin{array}{l}\text { Background: There is an increase in the prevalence rates of } \\
\text { overweight and obesity word wide. Body mass index (BMI)is } \\
\text { positively and independently associated with morbidity and mortality } \\
\text { from hypertension,cardiovascular diseases,type } 2 \text { diabetes mellitus and } \\
\text { other chronic disease.Itis against this background,this research } \\
\text { corroborate similar result in Al-Mussayib district. } \\
\text { Objectives: The objective is to determine the relationship between } \\
\text { BMI and blood pressure among adults in Al-Mussayib district. } \\
\text { Materials and Methods: WHO STEP wise questionnaires modified to } \\
\text { obtain information on lifestyle, Demographic, Weight and height were } \\
\text { measured using digital influence scale and stadiometer. BP was } \\
\text { measured using mercury sphygmomanometer. Threemeasurements were } \\
\text { taken at about } 10 \text { mint intervals. } \\
\text { Results: The prevalence of overweight was (19.7\%) and obesity was } \\
\text { found to be ( } 11.8 \% \text { ) and } 7.5 \% \text {, About(17.8 \%) of the (422)participants } \\
\text { were hypertensive and a significant difference existed between high } \\
\text { systolic blood pressure and normal systolic blood pressure of the } \\
\text { participants (p=0.01). } \\
\text { Conclusion: The relationship is that any increasing in BMI positively } \\
\text { influenced BP among these study of adults ' population. }\end{array}$ \\
\hline
\end{tabular}

Copy Right, IJAR, 2020,. All rights reserved.

\section{Introduction:-}

Hypertension is one of the important preventable non communicable disease (NCD) and risk factor for premature death and disability in many developing nations in Asia ${ }^{(1)}$. In the majority of European countries, the prevalence of obesity y increased by $10 \%-40 \%$ between 1980 and the late 1990s. current rates of Obesity in European countries are in the range $10 \%-20 \%$ for men $10 \%-25 \%$ for women ${ }^{(4)}$. According to statistics from the centers for disease control and Prevalence, in 1994, $56 \%$ of the USA population were classified as obese and about one third of worlds adult population are hypertensive according to recent reports ${ }^{(5)}$. In 2002, the overweight figure was $65 \%$ and the obesity figure was $31 \%(5)$. A community-based survey was conducted on A nationally representative sample of 25-65 years of age in 2006, the prevalence of hypertensionin Iraq was 30\% and it was higher among males than females ${ }^{(6)}$. The burden of hypertension is increasing particularly in the low and middle-income countries $^{(7)}$. According to the world health organization, overweight and obesity are now so common that they are replacing under nutrition and infectious diseases in many developing countries ${ }^{(8)}$. Globally, there are now as many over nourished people as undernourished people ${ }^{(9)}$. Theoverall prevalence of high blood Pressure (BP) in adults aged 25 and over was around $40 \%$ in 2008. The proportion of the world's population with high BP or uncontrolled hypertension fell modestly between 1980 and $2008^{(10)}$. Body mass index (BMI) is calculated from height and 
weight $\left(\mathrm{kg} / \mathrm{m}^{2}\right)$ using standardized examination protocols ${ }^{(11)}$. The WHO classifies BMI as normal $\left(18.5-25 \mathrm{~kg} / \mathrm{m}^{2}\right)$, overweight $\left(20-30 \mathrm{~kg} / \mathrm{m}^{2}\right)$, and obese $\left(>30 \mathrm{~kg} / \mathrm{m}^{2}\right)^{(12,13)}$. BP is the pressure of the resistance of blood flow against the walls of the arteries ${ }^{(13)}$. Systolic blood pressure (SBP) is the top number refers to the amounts of pressure in your arteries during Contraction of your heart muscle. Diastolic pressure, however, is the pressure required to allow constant Flow in the blood vessels and filling of the ventricles before the next systole ${ }^{(14)}$ according to Saxon et al. high BP is defined as a systolic reading of $=>140 \mathrm{~mm} \mathrm{hg}$ and $/$ or higher over a diastolic reading $=<90 \mathrm{~mm} \mathrm{hg}$. Assessing association between body mass index and hypertension has important public health implication in Asian countries, where the burden of hypertension is high and obesity is increasing at the population level ${ }^{(16,17,18)}$.

Several epidemiological studies shown that a positive correlation between BMI and hypertension ${ }^{(13)}$ Winnick ${ }^{(14)}$ observed thatthe cause of overweight and obesity are multifaceted, some factors seem to play a significant role, such as consuming too muchcalories coupled with not physical exercising enough to burn out the excess calories, combination that easily result in becomingoverweight.The main objective was to determine the relationship between BMI and BP of adults in Mussayib, Iraq.

\section{Materials and Methods:-}

WHO STEP wise questionnaires were modified to collect lifestyle information and anthropometric measurements (weight and height) were taken using the standardized instruments andprocedures.BMI was then calculated by dividing body weight $(\mathrm{kg})$ by squared height $\left(\mathrm{m}^{2}\right)$.We classified participants(422) into four groups according to the conventionalWord Health Organization (WHO)classification system ${ }^{(19)}$.Blood pressure was measured for participants using standard protocol ${ }^{(20)}$. Three measurements were taken at seating position,at about 10 mints intervals and the mean of the second and third measurementwas used.

\section{Data analyses:}

Chi-square analysis was used to determine the association between variables Such as BMI and BP,(underweight, normal weigh,over weight and obese)with (high B P and normal B P). BMI classification was $=<18.5 \mathrm{~kg} / \mathrm{m}^{2}=$ underweight ; $18.5-25 \mathrm{Kg} / \mathrm{m}^{2}=$ normal ; and $26-30=$ overweight and $>30 \mathrm{Kg} / \mathrm{m}^{2}=$ obesity ${ }^{(9)} \mathrm{BP}$ was classified as high or normal according to the classification of $\mathrm{SBP}$ (high $=>140 \mathrm{~mm} \mathrm{hg}$ ).and normal $<140 \mathrm{~mm} \mathrm{hg}$.

\section{Results and Analysis:-}

Table 1:

describes the background characteristics of the participants. Differences in the occupations engaged by the participants and levels of education ofboth sexes.No significant difference in the level of education, large proportion of females and males were educated as compared to the females.

\section{Table 2:}

The life style variables of respondents. Only (22.7) of the participants engaged in any exercise.About (8.5\%)were smokers.

Table 3:

Shows the BP profile of respondents. $17.8 \%$ of the study population had high BP, while $82.2 \%$ had normal BP, more the overweight and obese participants had high BP than normal and underweight.

\section{Figure 1:}

Percentage of BMI classifications of the respondents. Majority of the people were normal BMI (55.7\%).About $19.7 \%$ were overweight while $11.8 \%$ were obese.

\section{Figure 2:}

Shows the percentage distribution of BMI classification of respondents according to sex. Majority of the males were ofnormal BMI (36.2\%). Females were overweight and obese more than males. Among $11.8 \%$ of the sample population that wereobese, $7.8 \%$ were females while $4 \%$ were males.

\section{Figure 3:}

Percentage of body mass index distribution of respondents according to level of exercise. 


\section{Figure 4:}

Distribution of BMI classification based on age groups. BMI was observed to increase with an increase in age. Highest percentage of participants of a normal BMI among the age groups was $26.7 \%$, which was recorded by the 18-24 years' group and the highest percentage of participants of obese among the age group above 39 years $7 \%$. Furthermore, only $1.3 \%$ of the age group 18-24 age were obese.Table 2: show the variables of the of life style of the study participants only (22.7)of the respondents engaged in exercise and (8.5\%) smoked cigarette.

Table 1:- Background characteristics of respondents $(n=422)$.

\begin{tabular}{|c|c|c|c|c|}
\hline $\begin{array}{c}\text { Characteristics Age } \\
\text { (years) }\end{array}$ & Total, $\mathrm{n}(\%)$ & Male $(\mathrm{n}=226), \mathrm{n}(\%)$ & $\begin{array}{c}\text { Females } \\
(\mathrm{n}=196), \mathrm{n}(\%)\end{array}$ & $\mathrm{P}$ \\
\hline $\begin{array}{c}18-24 \\
25-31 \\
32-38 \\
39-\text { Above }\end{array}$ & $\begin{array}{c}166(39.5) \\
68(16) \\
59(14) \\
12(30.5)\end{array}$ & $\begin{array}{c}114(27) \\
30(7) \\
27(6.5) \\
55(13)\end{array}$ & $\begin{array}{c}52(12.5) \\
38(9) \\
32(7.5) \\
74(17.5)\end{array}$ & \multirow{3}{*}{$\mathrm{P}<0.05$} \\
\hline $\begin{array}{c}\text { Occupation } \\
\text { Free business } \\
\text { House wife } \\
\text { Officer } \\
\text { Teacher } \\
\text { Farmer }\end{array}$ & $\begin{array}{c}53(12.5) \\
76(18) \\
93(22) \\
40(9.5) \\
160(38)\end{array}$ & $\begin{array}{c}53(12.5) \\
--- \\
65(15.5) \\
11(2.5) \\
97(23)\end{array}$ & $\begin{array}{c}---- \\
76(18) \\
28(6.5) \\
29(7) \\
63(15)\end{array}$ & \\
\hline $\begin{array}{c}\text { Level of Education } \\
\text { Read and write } \\
\text { Primary School } \\
\text { middle School } \\
\text { secondary School } \\
\text { College } \\
\text { postgraduate }\end{array}$ & $\begin{array}{c}116(27.5) \\
51(12) \\
72(17.0) \\
97(23.0) \\
25(6.0) \\
61(14.5)\end{array}$ & $\begin{array}{l}42(10) \\
51(12) \\
42(10) \\
46(11) \\
15(3.5) \\
30(7.0)\end{array}$ & $\begin{array}{c}74(17.5) \\
30(7.5) \\
51(12) \\
10(2.5) \\
31(7.5) \\
2(0.4)\end{array}$ & \\
\hline
\end{tabular}

Table 2:- Lifestyle variables.

\begin{tabular}{|c|c|c|c|c|}
\hline Characteristics & Total, $\mathrm{n}(\%)$ & Male, $\mathrm{n}(\%)$ & Females, $\mathrm{n}(\%)$ & $\mathrm{P}$ \\
\hline \multicolumn{5}{|c|}{ Do you engage in any exercise? } \\
\hline Yes & $96(22.7)$ & $86(20.3)$ & $10(2.4)$ & \multirow{2}{*}{$<0.01$} \\
\hline No & $326(77.2)$ & $140(33.0)$ & $186(44.2)$ & \\
\hline \multicolumn{5}{|c|}{ Do you Smoke Cigarette? } \\
\hline Yes & $36(8.5)$ & $34(8)$ & $(0.5)$ & \multirow{2}{*}{0.01} \\
\hline No & $386(91.5)$ & 192(45.0) & 194(46.5) & \\
\hline
\end{tabular}

Table 3:- Blood pressure profile of respondents.

\begin{tabular}{|c|c|c|c|c|}
\hline Feature & Total, n $(\%)$ & Male , $\mathrm{n}(\%)$ & Females , n $(\%)$ & $\mathrm{P}$ \\
\hline \multicolumn{5}{|l|}{ SBP } \\
\hline High & $130(32.5)$ & $70(17.5)$ & $60(15.0)$ & \multirow{2}{*}{----} \\
\hline Normal & $270(67.5)$ & $136(34.0)$ & $134(33.5)$ & \\
\hline \multicolumn{5}{|l|}{ DBP } \\
\hline High & $92(25.0)$ & $44(11.0)$ & $48(12.0)$ & \multirow{2}{*}{---- } \\
\hline Normal & $308(77.0)$ & $162(40.5)$ & $146(36.5)$ & \\
\hline
\end{tabular}

SBP: Systolic Blood Pressure, DBP: Diastolic Blood Pressure.

Table 4:- The relationship Between Body mass index and Blood Pressure of respondents.

\begin{tabular}{|c|c|c|c|c|}
\hline Feature (SBP) & High, $\mathrm{n}(\%)$ & Normal, $\mathrm{n}(\%)$ & \multicolumn{2}{|c|}{ Total } \\
\hline BMI & $4(0.9)$ & $50(11.8)$ & $54(12.8)$ & \\
\hline Underweight $<(18.5)$ & $38(9.3)$ & $197(46.3)$ & $235(55.7)$ & $\mathrm{P}<0.01$ \\
\hline Normal $(18.5-25.0)$ & $17(4.0)$ & $66(16.6)$ & $83(19.7)$ & \\
\hline Overweight $(26.0-30.0)$ & $17(4.0)$ & $36(8.5)$ & $50(11.8)$ & \\
\hline Obese $(>30.0)$ & &
\end{tabular}


$\mathrm{df}=3 \quad \mathrm{X}^{2}=12.2$

*Significant Difference Between BMI and SBP at P $<0.05 *\left(X^{2}=2\right)$

*BMI: Body Mass Index, SBP: Systolic Blood Pressure

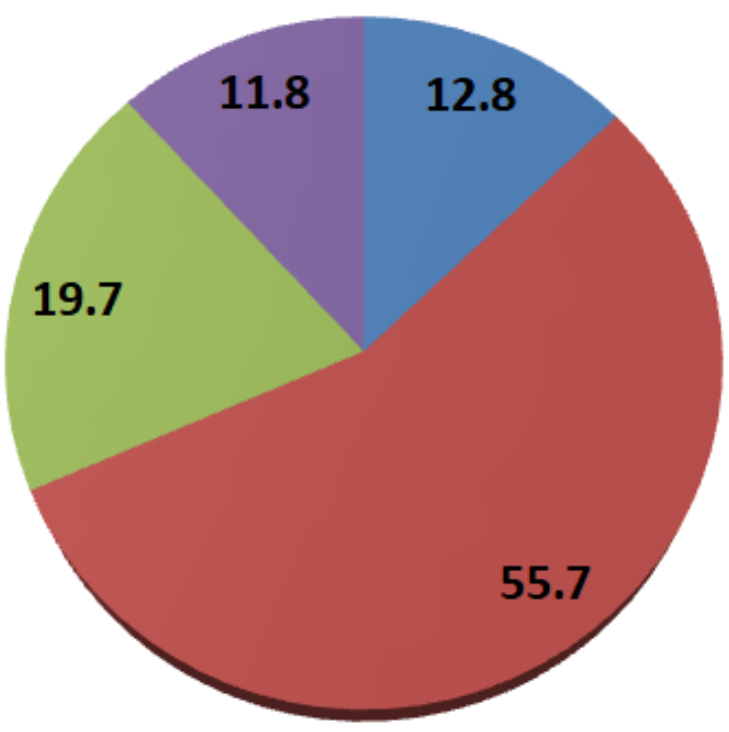

underweight

normal

overweight

obese

Fig 1: Percentage distribution of body mass index classification of respondents

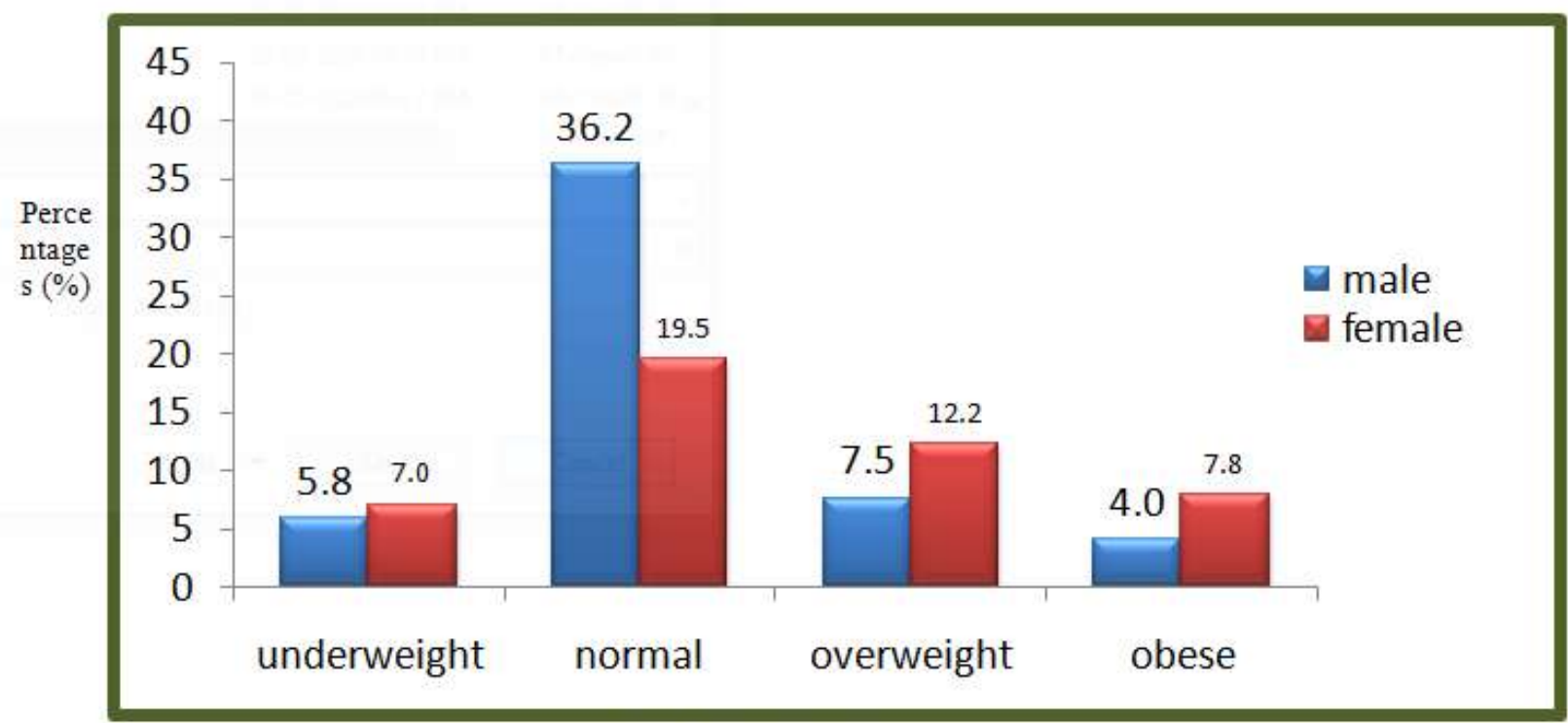

BMI Classifications

Fig 2: Percentage distribution of respondents' body mass index classification according sex 


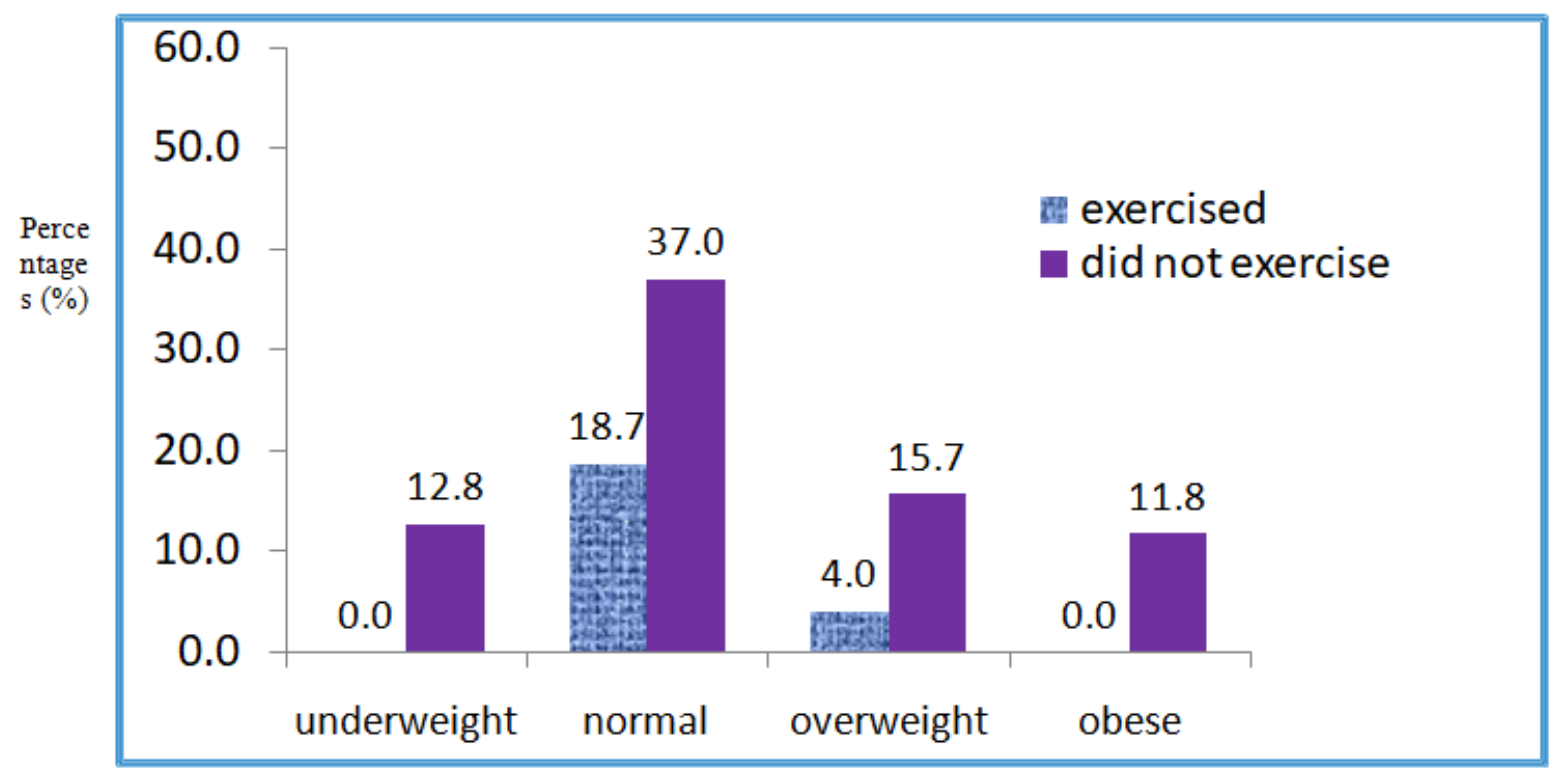

BMI Classifications

Fig 3: Percentage distribution of body mass index of respondents according to level of exercise

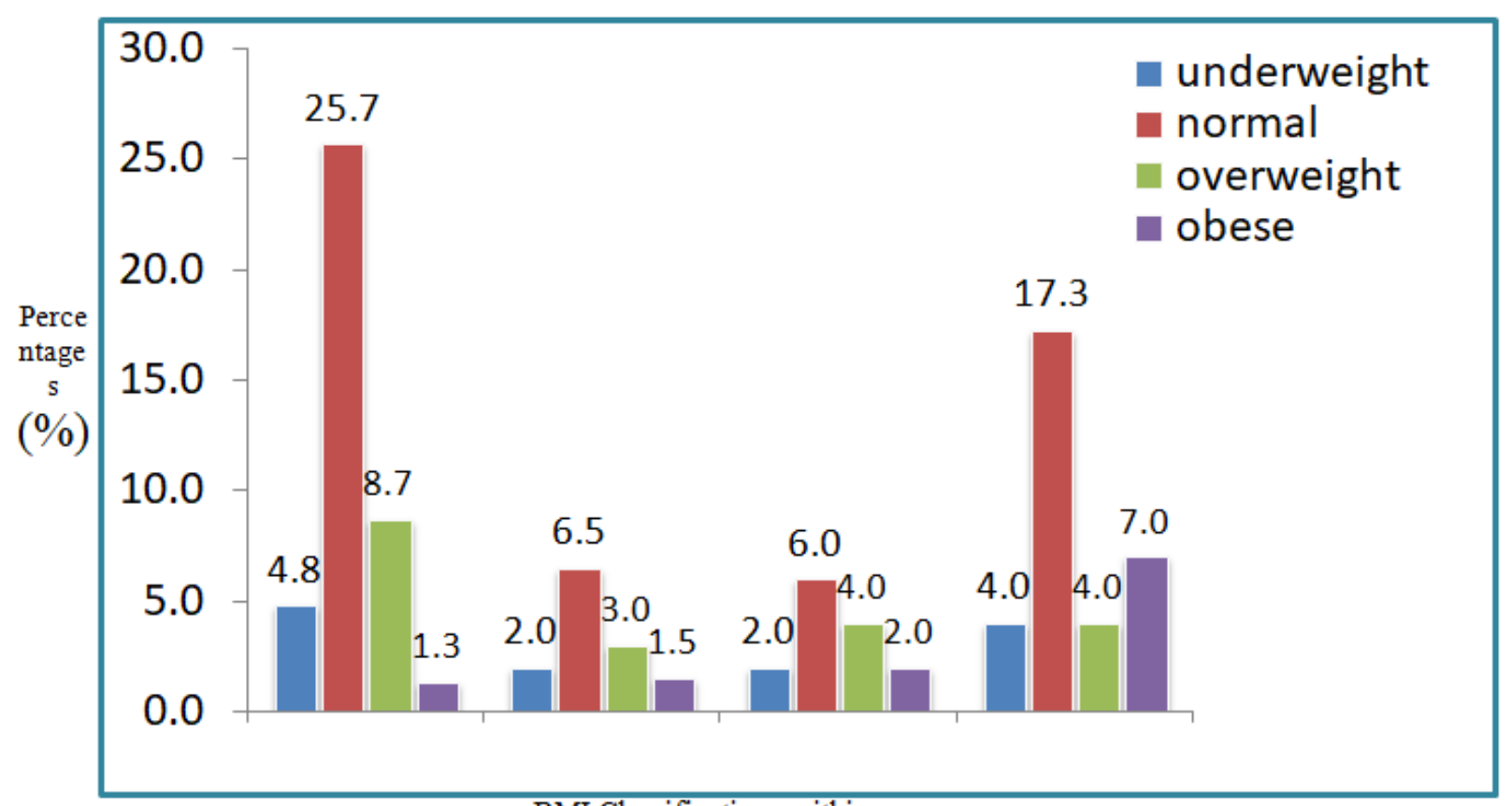

BMI Classifications within age groups

Fig 4: Percentage distribution of body mass index of respondents based on age groups

\section{Discussion:-}

BMI as a measure of body weight was classified according to the $\mathrm{WHO}^{(8)}$ as underweight, normal, overweight and obese. Overweight and obesity are risk factors for many diseases, including high $\mathrm{BP}{ }^{(15)} \mathrm{Hence}$, the prevalence of overweight and obesity is of a great importance to this study. 83 respondents $(19.7 .0 \%)$ were overweight and 50 (11.8\%) were obese.

Females had a higher prevalence of overweight and obesity than males. among the males, 32(7.5\%) were overweight while 17(4\%) was obese. The prevalence of overweight and obesity in females was 51(12.2\%) and $33(7.8 \%)$ respectively. This observation is in line with result from literature. For example, greedy ${ }^{(16)}$ observed in 
study on BMI and mortality that more women than men were obese in all age groups. This due to the fact that men are heavier work and more physically active than women.10(2.4\%) women engage in exercise while 86(20.3\%) men engage in exercise. A significant difference was observed between exercise in males and females $(\mathrm{p}<0.01)$. Also, it was found that men work longer hours than women.222 (55\%) Men work for 10-12h whereas120(28\%) women work for the same 10-12 $\mathrm{h}$. Since o physical activity increasing with manual working for most people, it implies that working manyhours will help to decrease the risk of becoming overweight or obese.

Age is a factor that affects the BMI of individuals acrossthe age groups, the highest rate of obesity (7.0\%) was recorded by the 39-above years' age group. The increased rate of obesitywith age could be due to the fact that older people are less physically active but maintain the same energyintake as during their earlier yearsand the excess energy that is not expanded is stored as fat, increasing their chances of becoming obese ${ }^{(17)}$.

A high prevalence of high BP was observed in this study, and 75(17.8. 0\%) of the participants were hypertensive (SBP greater orequal to $140 \mathrm{~mm} \mathrm{hg}$ ). In this study, there was a significant difference Between males and females on smoking $(\mathrm{p}=0.01)$. Only $2(0.5 \%)$ females smoke cigarette, while $34(8 \%)$ of the Male participantssmoke cigarette. Since smoking is a risk factor for high BP, this observation is not surprising. This places men at a greater risk of hypertension and its consequent diseases than women. BMI is not the best indicator of body fat. A high BMI does not necessarilymean there is increased body fat,but may be due to increased bone density or muscles,so that central adiposity gives a betterindication of body fat and can be used to show the relationship between body fat and BP. because of urbanization,people are becoming less physically active in recent time.

These days, most people prefer taking cars to walking.Furthermore, we do not engage in regular exercise. this study found that only $96(22.7 \%)$ of the respondents engage in exercise. Hence, it is not surprising that there is a high rate of overweight and obesity since a reduction in physical activity (sedentary lifestyle)Is a cause of overweight and obesity ${ }^{(13)}$.

From the result obtained in this study, it is very evident that overweight and obesityoccur as result of less physical activity. All the obese respondents do not engage in any form of exercise. Furthermore, theoverweight individuals who do not engage in any exercise were 66(15.7.0\%). Exercise is a very important factor to consider indecreasing the incidence of overweight and obesity in populations. This is because exercise helps the body to burn fat and excess calories. Consumption of energy in excess is one of the factors that lead to increased BMI (especially when it is coupled with less Physical Activity).

\section{Conclusion:-}

The prevalence of overweight in Al-Mussayib (19.7\%) and of obesity was (11.8\%). The obese Participants from females $(7.8 \%)$ and from males(4\%). The prevalence of high BP was recoded as $17.8 \%$ (SBP). An Association was found betweenincreasing BMI and hypertension. All the(11.6\%) obese people did not engage in any exercise. BMI also increased with an increase in age.

\section{References:-}

1. Forouzanfar Mohammad H, etal.Global, regional, and national comparative risk assessment of 79 behavioral, environmental and occupational and metabolic risk or clusters of risks ,1990-2015:a systematic analysis for the Global burden of disease study2015' Lancet .2016;383;10053(2016):1659-724.

2. Lawes CMM, Vander Hoorn s ,Rodgers A. Global burden of blood - pressure -related disease ,2001 Lancet (London, England) 2008;371:1513- 8.

3. Kearney PM, WheltonM,ReynoldsK,MuntnerP,WheltonPK,HeJ.Global burden of hypertension : analysis of word wide data .Lancet (London,England).2005; $365: 217-23$.

4. ChamberS R.Wakley G .Obesity and Overweight Matters in Primary Care UK :Radcliffe Publishing2002.

5. Farling P, Anesthesia and Uncommon - Diseases - 5th ed Philadelphia, USA : Saunders Elsevier, Br J Anaesth 2006 ; 97 : 904.

6. $\mathrm{Al}$ - Gasser N,A ; Alak M , Al-shemeriA.Chronic non - communicable disease risk factors survey in Iraq 2006.

7. Mills KT ,Bundy JD, Kelly TN, Ree JE, Kearney PM,Reynold K , e t al .Global disparities of hypertension prevalence and control : a systematic analysis of population -based studies from 90 countries circulation. $2016 ; 134: 441-50$. 
8. Gibson RS. Principles of Nutritional Assessment .USA : Oxford University Press ; 2005.

9. Diet, nutrition and the prevention of chronic diseases . World Health Organ Tech Rep Ser 2003 ; 916: i-viii ,1-149.

10. Galie N. Barbera JA, Frost AE, Ghofrani HA, Hoeper MM, McLanghlin VV, et al . Initial use of ambrisentan Plus tadalafil In pulmonary arterial hypertension. N Engle J Med 2015 ; 373: 834 - 44 .

11. Sizer FS. Piche LA Whitney EN. and E Whitney .Nutrition : concepts and Controversies . Toronto Canada : Cengage Learning ; 2012.

12. Pi -Sunyer FX .Medical hazards of obesity . Ann Intern Med 1993:119:655-66013. Martin E. Concise Colour Medical Dictionary. Great Clarendon Street, Oxford, UK: Oxford University Press ; 2015

13. Martin E.ConciseColour Medical Dictionary . Great Clasendon Street, Oxfordd, UK : Oxford University Press ; 2015

14. Suddarth D. Conditions of the prostate In Brunne LS, SuddarthDS, editors . The Lippincott Manual of Nursing Practice.Philadelphia : JB Lippincott Co .; 1991.

15. Truswell AS, Hiddink GJ, Blom J. Nutrition guidance by family doctors in a changing world : Problems, Opportunities, and Future possibilities Am J Clin Nutr 2003 ; 77: 1089S - 16.MisraA,Jaja warden R ,Anoops .Obesity in south Asia ;Phenotypesmorbidities and mitigation .Currobes ,Resp 201:8:43-52.

16. VR . Handbook of Anthropometry : Physical Measures of Human from in Health and Diseases . London UK : Springer Science \& Business Media ; 2012.

17. Ramachandran A, SnehalathaC.Rising burden of obesity in Asia J obes. 2010:2010:868573. https:lldoiorgl 10.1155120101868573.

18. . NeupaneD ,Mclachlan CS, Sharma R GyawaliB,Khanal, MishraSR: etal Prevalence of hypertension in member countriesof South Asia Association for Regional Cooperation (SAARC ):systematic review and Meta-analysis .Medicine (Baltimore).2014:93:e74 https:1l doi.org 110.1077lMD.0000000000000074.

19. Expet Panel on the Identification, Evaluation , and treatment of Overweight and Obesity in Adult .Executive summary of theclinical guideline on the identification, evaluation , and treatment of overweight and obesity in adult .Arch Intern Med. 1998,158(17):1855-67.

20. ICF International 1 Demographic and Health Surveys . Biomarker field Manual :Demographic and HealthSurvey MethodologyMaryland ,USA:2012 https: llwww . dhs program .com 1 publications 1 publication dhsm7-dhs-questionnaaires-and-manuals,cfm.

21. RolfesSR , Pinna K, Whitney E . Understanding Normal and Clinical Nutrition . Stanford USA :Cenngage Learning ;2014.

22. Khurana I . Essentials of Medical Physiology .India : Elsevier India ; 2008.PineoCB ,Hitzeroth II , Rybicki EP . Immunogenic assessment of plant - produced human papillomavirus Type 16L1 / L2chimaeras Plant Biotechnol J $2013 ; 11: 946-75$. 